\title{
Research on the impact of recreational activities on the patients of schizophrenia
}

\author{
Yazgi Erdogan ${ }^{1, *}$, Faruk Yamaner $^{1}$ and Emrah Karadere $^{2}$ \\ ${ }^{1}$ Hitit University Sport Sciences Faculty, Corum, 19030, Turkey \\ ${ }^{2}$ Hitit University Medical Faculty, Corum, 19030, Turkey
}

\begin{abstract}
This research was done for finding out the impacts of Recreational Activities on the Schizophrenic Patients. 30 patients diagnosed with schizophrenia registered in Hitit University Education and Research Hospital's Community Mental Health Centerwere included in the research. The patients were applied with educational games and folk dances as recreational activities three days a week for 12 weeks. In the research, Scale for the Assessment of the Negative Symptoms (SANS), Scale for the Assessment of the positive Symptoms (SAPS), Global Assessment of the Functioning (GAF) and Clinical Global Impression (CGI) scales were used as data collection tools at the beginning and the end of 12 weeks. In addition, body lipid percentages, body weights and body mass indexes (BMI) of the patients were calculated at the beginning and the end of the research by using TANITA device. According to the results of statistical analyses, the difference between start and end SANS $(p=0,471)$, GAF $(p=0,004)$, CGI $(p=0,003)$ values and body lipid percentages $(p=0,019)$ of the participants was statistically significant. However, the difference between start and end weight $(p=0,406)$, BMI $(p=0,471)$ and SAPS $(p=0,081)$ rates was not statistically significant.
\end{abstract}

\section{Introduction}

Schizophrenia is a disease which starts at early ages, occur equally in both genders, can be seen in all societies and individuals in all socio-economic levels and continues with deformations, improvements and relapses in especially thought, deception and sensation areas $(1,2)$. According to a systematic review, life-long prevalence of schizophrenia in Turkey was determined as 8.9/1000 in general of the society (3).

In today's conditions, it gets harder day-by-day for a healthy individual to have a job, to continue his/her job and to become an economically free individual. This situation is harder for an individual diagnosed with schizophrenia than the healthy individuals (4).

Schizophrenia is a disease which effects a person's all cognitive functions (such as sensation, attention, memory), emotions, behaviors and judgment. It may create insufficiency in many areas such as relations between people, self-care and life abilities. The patients who lose their abilities, whose quality of life is impaired and who do not work are easy to be excluded from the society and to get blacklisted (5).

*Corresponding author: yzg.erdgnn@gmail.com 
The signs of disease can be significantly removed with use of antipsychotic medicines and they are effective in all stages of antipsychotic treatment (start, fulminant and protective treatment (6).

However, rehabilitation programs which include art areas such as hand abilities, music, drawing, dance, folk dance are required in addition to the traditional treatment method evaluated as use of medicines (7).

It is thought that the physical activities impact the quality of life of the patients having mental diseases in two ways. The first one is that it increases physical health and the second is that it minimizes psychiatric and social discomfort (8).

The movements, pace, quickness, vitality, flexibility, force, stability in the folk dances are among important physical compatibility elements. The educational games also allow a person to relax physiologically and psychologically. It also eases compliance with the social life as well as it increases the impacts of treatment with game therapies. In this context, the purpose of this study is to review the impacts of 12-week educational games and folk dances to the treatment of the schizophrenia patients.

\section{Method}

\subsection{Research Group}

30 patients diagnosed with schizophrenia registered in Hitit University Education and Research Hospital's Community Mental Health Center were included in the research group.

\subsection{Training Places and Durations}

Trials were made under observation of the authorities for two weeks in order to provide adaptation, to see the lacks that may be present in the organization and to take feedbacks of the patients in terms of their motivations and the works were started after completing the lacks.

Educational games and folk dance works were done with the experimental group for totally twelve weeks as three times a week, for one hour on Monday, Wednesday and Friday in the sports hall of Hitit University's College of Medicine. The institution's psychiatrists and nurses took part in the works as observers.

Educational Games: Educational games were played between 10:00-11:00 on Monday and 10:00-10:30 on Friday for 12 weeks. The educational games included Twitch, Throw the Ball, Follow the Leader, Windmill Game, Run from the Rolling Ball, Taking and Giving up Hostage and Go Around and Get Position. It was given importance to make warm up for 10 minutes before the work and to make stretching moves for 10 minutes after the work.

Folk Dances: Folk dances were done between 10:00-11:00 on Wednesday and 10:3011:00 on Friday for 12 weeks. In folk dance works, 'Ata Bari' of Artvin region, 'AgirGovend' of Bitlis region, 'Toycular' of Van region, 'Harmandali' of Izmir region and 'Kirikhan' of Gaziantep region were taught to the participants. While selecting the games, it was considered whether they are played as mixture of males and females, whether they have plain figures and whether they can be played by everyone without need of a unique player. It was given importance to make warm up for 10 minutes before the work and to make stretching moves for 10 minutes after the work. 


\subsection{Collection of Data}

Body Composition Measurement: "Tanita Body Composition Analyze BC-418" bioelectric impedance analyzer was used for determination of body lipid percentages of the experiment group. The subjects were asked to stand on the platform with bare feet after entering the data to the analyzer's screen by reducing their lengths, ages, genders and weights of clothes for determining their body compositions. Body mass index (BMI), body lipid mass and body lipid percentage measurements were made.

Scale for the Assessment of the positive Symptoms (SAPS): It was developed by Andreasen in 1990 (9). In our country, availability and reliability works of this scale was made by Erkoç et al. in 1991. It consists of 34 items in total and 4 the sub scales as hallucinations, delusions, strange behaviors and formal thought disorders. Each item is assessed as *No symptom $=0$, *Suspicious $=1$, *Mild $=2$, *Middle $=3$, *Significant $=4$, *Strong $=5$ (10).

Scale for the Assessment of the Negative Symptoms (SANS): It was developed by Andreasen in 1990 (9). In our country, availability and reliability works of this scale was made by Erkoç et al. in 1991. It consists of totally 25 items and 5 sub scales as bluntness, alogia, decrease in energy and health, lack of enjoyment and social withdrawal and lack of attention. Each item is assessed as *No symptom $=0,{ }^{*}$ Suspicious $=1, *$ Mild=2, *Middle=3, *Significant $=4, *$ Strong $=5(10)$.

Clinical Global Impression Scale (CGI): It was developed by Guy in 1976. It is a scale used by the observer for determining the strenght of mental disorders or the improvements in the observation. In the study, CGI-Strength form was used for assessment of the strength of disease. The observer scales the strength or improvement of the disease between *Not Sick $=0$ and *Very Sick $=7$ according to the general experience of the observer about the aforementioned disease (11).

Global Assessment of the Functioning (GAF): It was developed by Hall in 1995. It provides assessment of the general functioning related to the psychiatric symptoms. It is a scale assessed by the clinician based on the information identified with ranges of 10 points on the measurement scale with 100 points. It is a scale which helps observation of clinical processes of the individuals with a single scale in a general frame. High points in the scale show that the functioning is high (12).

\subsection{Statistical Analysis}

The data obtained in this study were analyzed with IBM SPSS Statistics Version 20 package program. While making research on the normal distribution base of the variants, Shapiro Wilk's was used due to the unit numbers. 0,05 was used as the significance level while interpreting the results and it was mentioned that the variants are not due to normal distribution when $\mathrm{p}<0,05$ and variants are due to normal distribution when $\mathrm{p}>0,05$.

While inspecting the difference between two related variants, Wilcoxon Test was used as they are not due to normal distribution.

0,05 was used as the significance level while interpreting the results and it was mentioned that there is a significant difference when $\mathrm{p}<0,05$ and there is no significant difference when $\mathrm{p}>0,05$. 


\section{Findings}

Table 1. Frequency Distribution Table on Demographic Information

\begin{tabular}{llcc}
\hline \multirow{3}{*}{ Gender } & & n & \% \\
\hline \multirow{3}{*}{ Marital Status } & Memale & 11 & 36.67 \\
& Total & 19 & 63.33 \\
& Single & 30 & 100 \\
\hline & Married & 18 & 60 \\
& Divorced & 10 & 33.33 \\
& Total & 2 & 6.67 \\
\hline
\end{tabular}

$36,67 \%$ of the participants are female and $63,33 \%$ are male. Regarding the marital status, $60 \%$ of them are single, $33,33 \%$ are married and $6,67 \%$ are divorced.

Table 2. Distribution Table on the Values

\begin{tabular}{lcccccc}
\hline & $\mathrm{n}$ & Mean & Median & Min & Max & ss \\
\hline Session Participation Rate & 30 & 23.97 & 26 & 5 & 36 & 10.41 \\
Age & 30 & 41.23 & 40 & 24 & 64 & 10.22 \\
\hline
\end{tabular}

The session participation rate is around 23.97. Age values are 41 in average.

Table 3. Results of Wilcoxon Test on the Difference between Times in terms of Weight Values

\begin{tabular}{|c|c|c|c|c|c|c|c|c|c|}
\hline & \multirow[b]{2}{*}{$\mathrm{n}$} & \multirow[b]{2}{*}{ Mean } & \multirow[b]{2}{*}{ Median } & \multirow[b]{2}{*}{ Min } & \multirow[b]{2}{*}{ Max } & \multirow[b]{2}{*}{ ss } & \multicolumn{3}{|c|}{ Wilcoxon Test } \\
\hline & & & & & & & Item Ave. & $\mathrm{z}$ & $\mathrm{p}$ \\
\hline Weight 1 & 30 & 87.1 & 87 & 63 & 143 & 16.34 & 16.73 & 0688 & 0402 \\
\hline Weight 2 & 30 & 85.03 & 84.5 & 61 & 145 & 17.42 & 11.46 & -0.000 & 0.492 \\
\hline
\end{tabular}

There is no statistically significant difference between times in terms of weight values $(\mathrm{p}>0,05)$. The value after weight is lower and it is not statistically significant.

Table 4. Results of Wilcoxon Test on the Difference between Times in terms of body mass index (BMI)

\begin{tabular}{cccccccccc}
\hline & & & & & \multicolumn{5}{c}{ Wilcoxon Test } \\
\hline & $\mathrm{n}$ & Mean & Median & Min & Max & ss & Item Ave. & z & $\mathrm{p}$ \\
\hline BMI 1 & 30 & 31.85 & 31.25 & 21.78 & 48.9 & 5.89 & 16.85 & & \\
\hline BMI 2 & 30 & 31.04 & 30.08 & 23.04 & 49.59 & 6.2 & 11.36 & & \\
\hline
\end{tabular}

There is no statistically significant difference between times in terms of BMI values $(\mathrm{p}>0,05)$. The value after BMI is lower and it is not statistically significant.

Table 5. Results of Wilcoxon Test on the Difference between Times in terms of body lipid percentage

\begin{tabular}{lccccccccc}
\hline & \multicolumn{1}{c}{} & \multicolumn{1}{c}{} & & \multicolumn{4}{c}{ Wilcoxon Test } \\
\hline & $\mathrm{n}$ & Mean & Median & Min & Max & ss & Item Ave. & z & p \\
\hline Body Lipid Percentage 1 & 18 & 35.97 & 37.55 & 21.7 & 50.6 & 8.7 & 9.69 & \multirow{2}{*}{-2.344} & $0,019^{*}$ \\
\hline Body Lipid Percentage 2 & 29 & 31.89 & 33 & 15.5 & 58.9 & 10.16 & 6.75 & & \\
\hline
\end{tabular}


There is no statistically significant difference between times in terms of body lipid percentage values $(p>0,05)$. The value after body lipid percentage is significantly lower than the value before body lipid percentage.

Table 6. Results of Wilcoxon Test on the Difference between Times in terms of Points of Negative Symptom Scale

\begin{tabular}{lccccccccc}
\hline & & & & & \multicolumn{6}{c}{ Wilcoxon Test } \\
\hline & $\mathrm{n}$ & Mean & Median & Min & Max & ss & Item Ave. & z & p \\
\hline Negative Symptom Scale 1 & 30 & 42.3 & 41 & 9 & 81 & 17.77 & 13.26 & \multirow{2}{*}{-3.524} & 0,001* \\
\hline Negative Symptom Scale 2 & 30 & 41.17 & 40.5 & 10 & 80 & 18.05 & 6 & & \\
\hline
\end{tabular}

There is no statistically significant difference between times in terms of negative symptom scale points $(\mathrm{p}<0,05)$. The point after the negative symptom scale is significantly lower than the point before the negative symptom scale.

Table 7. Results of Wilcoxon Test on the Difference between Times in terms of Points of Positive Symptom Scale

\begin{tabular}{|c|c|c|c|c|c|c|c|c|c|}
\hline & \multirow[b]{2}{*}{$\mathrm{n}$} & \multirow[b]{2}{*}{ Mean } & \multirow[b]{2}{*}{ Median } & \multirow[b]{2}{*}{ Min } & \multirow[b]{2}{*}{ Max } & \multirow[b]{2}{*}{ Ss } & \multicolumn{3}{|c|}{ Wilcoxon Test } \\
\hline & & & & & & & Item Ave. & $\mathrm{z}$ & $\mathrm{p}$ \\
\hline Positive Symptom Scale 1 & 30 & 24.53 & 22 & 1 & 70 & 14.59 & 9.62 & 1742 & 0081 \\
\hline Positive Symptom Scale 2 & 30 & 23.9 & 21 & 1 & 65 & 13.67 & 9.2 & -1.143 & 0.001 \\
\hline
\end{tabular}

There is no statistically significant difference between times in terms of positive symptom scale points $(\mathrm{p}>0,05)$. The value after the positive symptom scale is lower and it is not statistically significant.

Table 8. Results of Wilcoxon Test on the Difference between Times in terms of Points of General Assessment of Functioning

\begin{tabular}{|c|c|c|c|c|c|c|c|c|c|}
\hline & & & & & & & \multicolumn{3}{|c|}{ Wilcoxon Test } \\
\hline & $\mathrm{n}$ & Mean & Median & Min & Max & ss & $\begin{array}{l}\text { Item } \\
\text { Ave. }\end{array}$ & $\mathrm{z}$ & $\mathrm{p}$ \\
\hline $\begin{array}{l}\text { General Assessment of } \\
\text { Functioning } \\
\text { Scale 1 }\end{array}$ & $\begin{array}{l}3 \\
0\end{array}$ & 44.83 & 45 & 30 & 65 & $\begin{array}{l}9 . \\
0 \\
5\end{array}$ & 9.63 & - & \\
\hline $\begin{array}{l}\text { General Assessment of } \\
\text { Functioning } \\
\text { Scale } 2\end{array}$ & $\begin{array}{l}3 \\
0\end{array}$ & 48.83 & 50 & 25 & 75 & $\begin{array}{l}1 \\
1 . \\
0 \\
4\end{array}$ & 11.92 & $\begin{array}{c}2.91 \\
2\end{array}$ & $\begin{array}{c}0,004 \\
*\end{array}$ \\
\hline
\end{tabular}

There is no statistically significant difference between times in terms of General Assessment of Functioning Scale points $(p<0,05)$. The point before the general assessment of functioning scale is significantly lower than the point after the general assessment of functioning scale. 
Table 9. Results of Wilcoxon Test on the Difference between Times in terms of Points of Clinical Global Impression Scale

\begin{tabular}{|c|c|c|c|c|c|c|c|c|c|}
\hline & & & & & & & \multicolumn{3}{|c|}{ Wilcoxon Test } \\
\hline & $\mathrm{n}$ & Mean & Median & Min & Max & ss & $\begin{array}{l}\text { Item } \\
\text { Ave. }\end{array}$ & $\mathrm{z}$ & $\mathrm{p}$ \\
\hline $\begin{array}{l}\text { Clinical Global Impression } \\
\text { Scale } 1\end{array}$ & $\begin{array}{l}3 \\
0\end{array}$ & 4.77 & 5 & 4 & 6 & $\begin{array}{l}7 \\
7\end{array}$ & 8 & - & 0,003 \\
\hline $\begin{array}{l}\text { Clinical Global Impression } \\
\text { Scale } 2\end{array}$ & $\begin{array}{l}3 \\
0\end{array}$ & 4.33 & 4 & 3 & 6 & $\begin{array}{l}7 \\
1 \\
\end{array}$ & 16 & 2.982 & $*$ \\
\hline
\end{tabular}

There is no statistically significant difference between times in terms of clinical global impression scale points $(\mathrm{p}<0,05)$. The point after the clinical global impression scale is significantly lower than the point before the clinical global impression scale.

\section{Conclusion, Discussion and Suggestions}

As result of the research, it was found that there is reduction in the negative symptom levels of the schizophrenia patients and no reduction in the positive symptom levels (13) with the recreational activities. This finding is in compliance with the negative symptom scale in the other study findings that found reduction in psychiatric symptoms related to the increase of physical activities of schizophrenia patients, however, it is not in compliance with the positive symptom scale (14). In these researches, it is also mentioned that application of physical exercises is related to increase of quality of life $(14,15)$ and increase in functioning $(15,16)$. It is an expectable finding that we may have determined a significant increase in the points of general assessment of functioning as result of an approach that may increase quality of life and functioning. It can also be said that new socialization and entertainment possibilities offered by the recreational activities may have been effective in determination of these changes.

There was no significant change in body weights and BMIs of the schizophrenia patients after the recreational activities. It is claimed that the physical exercises have not been effective on weight loss induction (17). The fact that there has been no difference in the physical measurements although there have been increase in the psychiatric symptoms and quality of life as result of application of regular physical activities on the schizophrenia patients supports this claim (14). In another review, it was found that exercise approaches are not effective in BMI in schizophrenia (16). These literature findings support our study. It can also be said that the duration limited to 12 weeks and no diet program applied together with the physical exercises may have been effective in stability of measurements such as BMI and body weight in patients.

We can say that similar studies to be made on more schizophrenia patients with longer durations may present comprehensive findings in this field, thus they may contribute on treatments of schizophrenia patients by drawing attention on increase of approaches on applying more physical activities in the treatments.

This research and application study was limited to the patients diagnosed with schizophrenia in Hitit University Education and Research Hospital's Community Mental Health Center. In the research, educational games and folk dances were inspected as recreational activities. The suggestions developed as result of this research are given below. 
- More added value can be provided on treatments of schizophrenia patients by increasing varieties of the educational games.

- Giving awards to the most successful ones among the schizophrenia patients during the educational games shall also be very important in learning and realizing the success criteria. - More schizophrenia patients can be accessed by increasing the varieties of folk dances.They can have more energy and willingness in life.

- Positive feedbacks shall be taken if this kind of abilities are given also to the relatives of the schizophrenia patients. Because, self confidences of the patients shall increase as they start producing new things. And the families shall be the first ones to recognize these changes.

- They shall be able to actively live like the other individuals in the society.

- Comparisons can be made between those who newly begin the treatment and those who were treated before.

Generally, the schizophrenia patients have felt very well as they made sports and played games in this study. It was observed that the participants were generally very happy. It was observed that these people have socialized with the other patients. In addition, the patients who participated in this study mentioned that the mentors have been extremely helpful against them when they had difficulties in some games and sport activities. It is clear that activity treatment in schizophrenia patients shall have many benefits both nationally and internationally.

\section{References}

1. ArslantaşHülya, Adana Filiz, (2011), ŞizofrenininBakımVerenlereYükü. PsikiyatrideGüncelYaklaşımlar, 3 (2), 251-277.

2. ÖzçelikBaşak,.(2002).,SüregenpsikotikBozukluğu Olan HastalarınTedavi, BakımVeUyumSorunlarıBağlamındaBakırköyRuhVeSinirHastalıklarıĔ̈itimVeAraştırm aHastanesi'ndekiUygulamalarVeYaşananGüçlükler. Düşünen Adam 2002, 15(2): 85 89.

3. BinbayTolga, UlaşHalis, ElbiHayriye, AlptekinKöksal, (2011),Türkiye'dePsikozEpidemiyolojisi:

YaygınlıkTahminleriveBaşvuruOranları ÜzerineSistemakBirGözdenGeçirme,

TürkPsikiyatriDergisi, 22: 40-52.

4. Yıldız Mustafa. (2009).,ŞizofreniRuhsalVeToplumsalTedaviGirişimleri. İçinde: Ceylan E, Çetin M, Editörler. Şizofreni. 4Baskı. İstanbul: İncekarakağıtMatbaası; 2009.14031413.

5. YanıkMedaim.(2007).,TürkiyeRuhSă̆lı̆̆lSistemiÜzerineDeğerlendirmeVeÖneriler, RuhSağllğıEylemPlanıÖnerisi.

PsikiyatrideDerlemeler, OlgularveVarsayımlar;(özelsayı):16-20.

6. Remington GI, Adams ME (1994),.Depotneuroleptics. Schizophrenia: ExploringtheSpectrum of Psychosis, Editedby RJ Ancill, S Holliday, J Higenbotham, New York, Wiley.

7. KöroğluErtuğtul, GüleçCengiz.,(2007), Şizofreniİçinde. PsikiyatriTemelKitabı. 2. Baskı. Ankara: Hyb Basın Yayın; 184-205.

8. Caroline, R.,Richardson M.D., Faulkner, G., McDevitt, J., SkrinarGary, S., Hutchinson, Dori S., Piette John D. (2005), IntegratingPhysical Activity IntoMentalHealth Services forPersonsWithSerioucMentalllness. Psychiatric Services.;Vol. 56No.3, 30-50.

9. AndreasenNC., (1990),Methods For Assessing Positive And Negative Symptoms. ProblPharmacopsychiatry, 1990; 24: 73-88 
10. AydemirÖmer, KöroğluErtuğrul, (2006), PsikiyatrideKullanılanKlinikÖlçekler, 3: 346353.

11. Guy W. (1976),ECDEUAssessment Manual for Psychopharmacology, Revised US Dept Health, Education and Welfare publication (ADM), Rockville, National Institute of Mental Health, p.76-338.

12. Hall, R. C. (1995). Global assessment of functioning: a modified scale. Psychosomatics, 36(3), 267-275.

13. Açıl, Arzu Anıl, 2006, ŞizofrenikHastalardaFizikselEgzersizinRuhsal Durum VeYaşamKalitesiÜzerineEtkisi,

CumhuriyetÜniversitesiSağlıkBilimleriEnstitüsüHemşirelikProgramı, YüksekLisansTezi, Sivas.

14. Sturludóttir K, Gestsdóttir S, Rafnsson RH, Jóhannsson E.(2015).,The Effects Of Physical Activity Intervention On Symptoms In Schizophrenia, Mental Well-Being And Body Composition In Young Adults. Laeknabladid 2015;101(11):519-24.

15. Dauwan M, Begemann MJ, Heringa SM, Sommer IE, (2016), Exercise Improves Clinical Symptoms, Quality of Life, Global Functioning, and Depression in Schizophrenia: A Systematic Review and Meta-analysis. Schizophr Bull 2016;42(3):588-99.

16. Firth J, Cotter J, Elliott R, French P, Yung AR.(2015), A systematic review and metaanalysis of exercise interventions in schizophrenia patients. Psychol Med. 2015;45(7):1343-61.

17. Krogh J, Speyer H, Nørgaard HC, Moltke A, Nordentoft M.(2014),Can Exercise Increase Fitness And Reduce Weight In Patients With Schizophrenia And Depression? Front Psychiatry 2014;5:89. 